\title{
Preparation and characterization of ascorbic acid-mediated chitosan-copper oxide nanocomposite for anti-microbial, sporicidal and biofilm-inhibitory activity
}

\author{
S. Logpriya ${ }^{1}$ - V. Bhuvaneshwari ${ }^{1}$ - D. Vaidehi ${ }^{1}$ 'R. P. SenthilKumar ${ }^{1} \cdot$ R. S. Nithya Malar ${ }^{1} \cdot$ B. Pavithra Sheetal ${ }^{1}$. \\ R. Amsaveni ${ }^{1} \cdot$ M. Kalaiselvi ${ }^{2}$
}

Received: 5 June 2018 / Accepted: 20 July 2018 / Published online: 14 August 2018

(C) The Author(s) 2018

\begin{abstract}
The chitosan-copper oxide ( $\mathrm{Chi}-\mathrm{CuO})$ biopolymer nanocomposites were synthesized by a simple green chemistry method using ascorbic acid as a reducing and capping agent. The intense peak around $300 \mathrm{~nm}$ was observed in the UV-visible spectrum indicating the formation of $\mathrm{CuO}$ nanoparticles. The prepared $\mathrm{Chi}-\mathrm{CuO}$ nanocomposites were characterized using energy-dispersive X-ray spectroscopy (EDX), scanning electron microscopy (SEM), X-ray diffraction spectroscopy (XRD), and Fourier transform-infrared spectroscopy (FT-IR). SEM and XRD pattern showed cubic shape for Chi-CuO nanocomposites with average crystalline size of $17 \mathrm{~nm}$, as calculated using Debye-Scherrer's formula. The FT-IR spectral studies showed the $\mathrm{Cu}-\mathrm{O}$ bond formation with chitosan to form nanocomposites. Synthesized nanocomposites showed significant anti-microbial activity against Bacillus subtilis, Pseudomonas aeruginosa, Escherichia coli and Penicillium notatum, assayed using the agar well diffusion method. It also showed sporicidal activity against $B$. subtilis and exhibited effective biofilminhibitory activity against $B$. subtilis $(69 \% / 100 \mu \mathrm{g} / \mathrm{mL})$ and $P$. aeruginosa $(63 \% / 100 \mu \mathrm{g} / \mathrm{mL})$.
\end{abstract}

V. Bhuvaneshwari

bhuvana_bt@yahoo.co.in

$1 \quad$ PG and Research Department of Biotechnology, Kongunadu Arts and Science College, Coimbatore 029, Tamilnadu, India

2 Department of Biochemistry, Kongunadu Arts and Science College, Coimbatore 029, Tamilnadu, India 


\section{Graphical abstract}
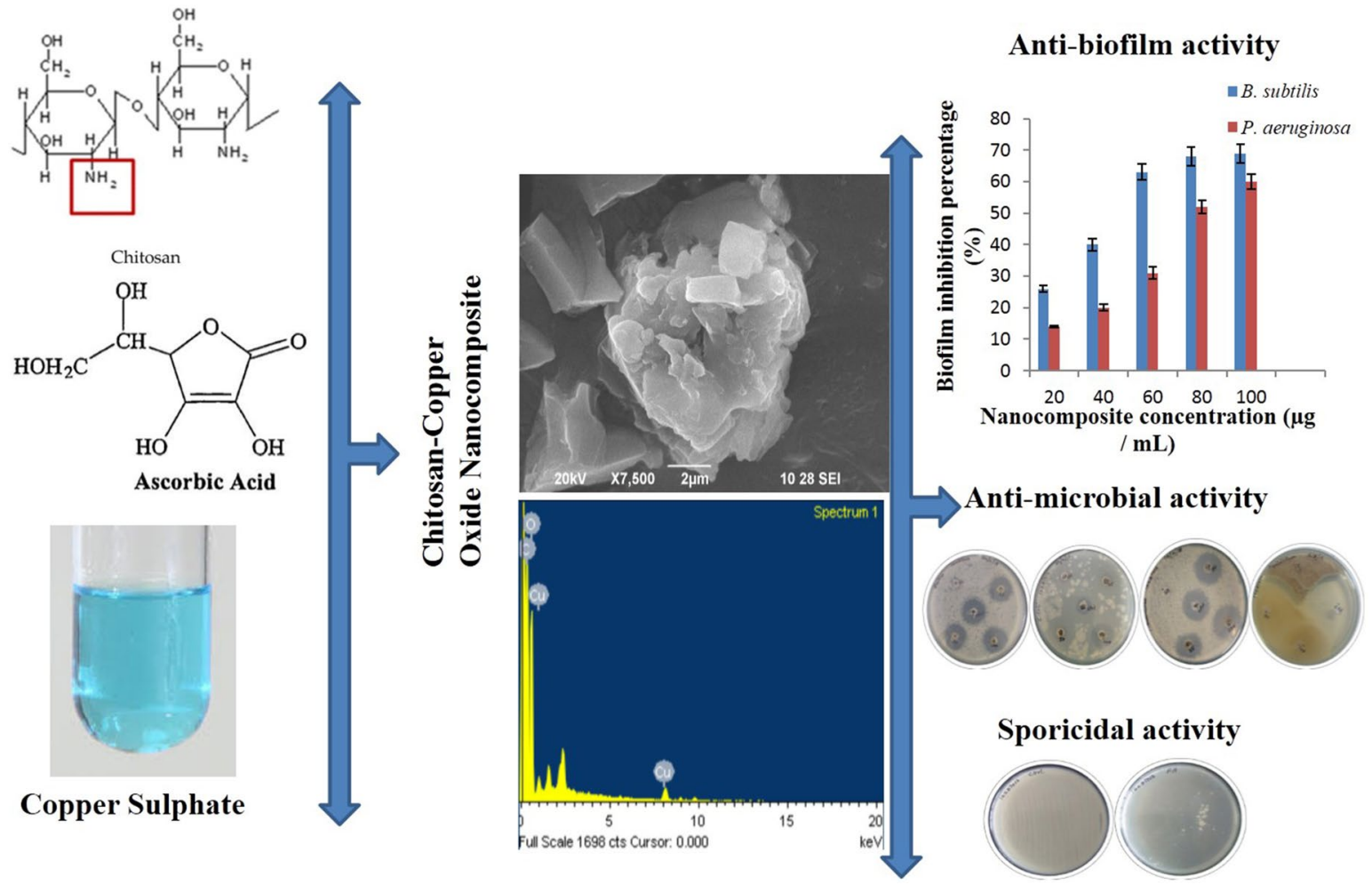

Keywords Biopolymer nanocomposites $\cdot$ Chitosan $\cdot$ Copper oxide $\cdot$ Anti-microbial activity $\cdot$ Biofilm inhibition activity

\section{Introduction}

Green synthesis of metal and metal oxide nanoparticles has attracted much attention than other nanoparticles synthesis methods such as microwave assist [1], phase transfer [2], electrochemical [3], sol-gel method and photochemical methods [4]. Green synthesis of metal and metal oxide nanoparticles using plants, microorganisms and bio-compounds is environmental friendly without using toxic compounds and involves simple preparation methods [5].

Nowadays, anti-microbial-resistant pathogens have been increasing with great frequency. Traditional medicine and some of the therapeutic drugs could not control the infections from microbial pathogens [6]. In recent years, metal oxide nanoparticles have gained attention for treating and preventing microbial pathogens. Among the metal oxide nanoparticles, copper oxide nanoparticle $(\mathrm{CuO})$ capped with biologically active molecules such as carbohydrates, vitamins and proteins are the new hope as nanoparticle agents to treat microbial pathogens [7].

The importance of polymers such as chitosan and chitin on metal oxide nanoparticles has attracted attention in the pharmaceutical and biological field [8]. Chitosan is a linear polysaccharide composed of randomly distributed $\beta$-( $1 \rightarrow 4)$-linked D-glucosamine and $\mathrm{N}$-acetyl-D-glucosamine (Fig. 1) with a number of commercial and biomedical uses [9]. Recently, chitosan-coated polypropylene films exhibited important antibacterial activity [10]. As chitosan is in a solid form, only organisms in direct contact with the active sites of chitosan are inhibited. The $\mathrm{CuO}$ nanoparticles enhance

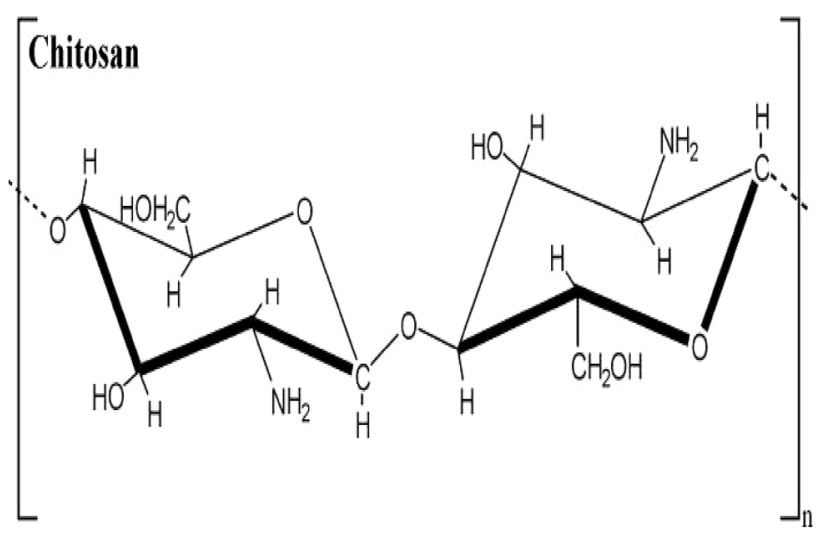

Fig. 1 Structure of chitosan biopolymer molecule 
the diffusivity of chitosan, so that it can be used as an effective anti-microbial agent [11]. The anti-microbial activity of chitosan may be enhanced with incorporation of $\mathrm{CuO}$ into chitosan as nanocomposite. In the present study, we prepared chitosan-coated copper oxide nanocomposites using ascorbic acid as a bio-template for the first time. Here, we have demonstrated the preparation, physical characterization of $\mathrm{Chi}-\mathrm{CuO}$ nanocomposites and its anti-microbial activity against bacterial and fungal pathogens, sporicidal and biofilm inhibition activity.

\section{Materials and methods}

\section{Materials}

Copper sulfate $\left(\mathrm{CuSO}_{4}{ }_{5} \mathrm{H}_{2} \mathrm{O}\right)$, ascorbic acid and acetic acid were purchased from Himedia Laboratories, Mumbai, India. Chitosan (medium molecular weight with $90 \%$ deacetylation) was obtained from Sigma-Aldrich. All other chemicals and reagents were of analytical grade.

\section{Preparation of $\mathrm{Chi}-\mathrm{CuO}$ nanocomposites}

About $0.2 \mathrm{~g}$ chitosan in $10 \mathrm{~mL}$ of $0.04 \%$ acetic acid was mixed with $90 \mathrm{~mL}$ of copper sulfate solution $(10 \mathrm{mM})$ containing $1 \%$ ascorbic acid and subjected to sonication for $30 \mathrm{~min}$. After sonication, the prepared solution mixture was then heated at 80 for $1 \mathrm{~h}$ using a heating mantle. This mixture resulted in yielding a brownish-black color precipitate. The obtained precipitate was filtered through a filter paper and dried at $100{ }^{\circ} \mathrm{C}$ overnight and then samples were dried and used for further studies.

\section{Characterization of Chi-CuO nanocomposites}

The formation of $\mathrm{CuO}$ and $\mathrm{Chi}-\mathrm{CuO}$ nanocomposites was confirmed using UV-visible spectroscopy (JASCO-V-670). UV absorbance spectral analysis was studied in the range from 200 to $500 \mathrm{~nm}$ at a resolution of $2 \mathrm{~nm}$. The surface morphology of $\mathrm{Chi}-\mathrm{CuO}$ nanocomposites was observed using scanning electron microscopy (SEM, Model-JEOL JSM-6400). The presence of elements was identified through energy-dispersive X-ray spectroscopy (EDX) attached with SEM. X-ray diffraction (XRD) analysis was carried out to determine the crystalline structure of the prepared $\mathrm{Chi}-\mathrm{CuO}$. $\mathrm{X}$-ray diffraction was recorded in the $2 \theta$ range from 10 to 90 at $40 \mathrm{kV} / 40 \mathrm{~mA}$ current with CuKa radiation (SHIMADZU, XRD-7000). The presence of bio and polymer functional groups that are responsible for the reduction, capping and formation of Chi-CuO samples was studied by FT-IR (SHIMADZU, Prestige 20 IR-Spectrometer).

\section{Anti-microbial activity}

The biocidal activity of Chi-CuO nanocomposite was investigated against Gram-positive (Bacillus subtilis ATCC 6633) and Gram-negative (Pseudomonas aeruginosa MTCC 2453 and Escherichia coli MTCC 443) bacterial strains and a fungus (Penicillium notatum), using the well diffusion method as described by Naika et al. [12]. Bacterial and fungal strains were swabbed on nutrient and potato dextrose agar plates, respectively, using cotton swabs. The required wells were made on agar plates with the help of gel puncture, after which it was impregnated with different concentrations of Chi-CuO $(25,50,100 \mu \mathrm{g} / \mathrm{mL})$ and gentamicin $(100 \mu \mathrm{g} / \mathrm{mL})$ was used as control; it was then incubated for $24 \mathrm{~h}$ to observe the zones.

\section{Biofilm inhibition activity}

The biofilm inhibition activity of Chi-CuO nanocomposites was determined using a method described by Bharathi et al. [13]. Each well of the sterile microtiter plate (96 wells) was filled with $90 \mu \mathrm{L}$ of Muller Hinton broth and inoculated with $10 \mu \mathrm{L}$ of test bacterial pathogens (B. subtilis and $P$. aeruginosa). To the above mixture, different concentrations of Chi-CuO composites $(20,40,60,80$ and $100 \mu \mathrm{g} / \mathrm{mL})$ were added and incubated for $24 \mathrm{~h}$ at $37^{\circ} \mathrm{C}$. The medium of each well was removed and excess adherent cells were washed with $0.3 \mathrm{~mL}$ of saline buffer to remove floating bacteria. Each well was stained with $0.4 \%$ crystal violet, and the excess stain washed using sterile water. After drying for $15 \mathrm{~min}$, the stains were solubilized with $100 \mu \mathrm{L}$ of $70 \%$ ethanol and read at $595 \mathrm{~nm}$ using an ELISA reader (BioRad-680, USA). The inhibitory percentage of biofilm formation was calculated as done by Bharathi et al. [13] and Barapatre et al. [14].

\section{In vitro sporicidal activity}

Bacillus subtilis culture was grown for 1 week at $37{ }^{\circ} \mathrm{C}$ on nutrient agar. Plates were scraped and the culture was suspended in 50\% ethanol. The suspended culture was then incubated at $22{ }^{\circ} \mathrm{C}$ for $2 \mathrm{~h}$ with agitation to lyse the vegetative bacteria. The suspension was centrifuged at $8000 \mathrm{rpm}$ for $20 \mathrm{~min}$ and the pellet was washed twice in cold distilled water. The spore pellet was resuspended in nutrient broth and used immediately for experiments. The typical digestive 
agar was autoclaved and cooled to $55^{\circ} \mathrm{C}$. About $250 \mu \mathrm{g} / \mathrm{mL}$ of $\mathrm{Chi}-\mathrm{CuO}$ nanocomposites was added into $25 \mathrm{~mL}$ of agar and continuously stirred while the plates were poured. About $10 \mu \mathrm{L}$ of spore preparation was plated. The plates were incubated for $24 \mathrm{~h}$ aerobically at $37^{\circ} \mathrm{C}$ and evaluated for growth.

\section{Results and discussion}

\section{Synthesis of Chi-CuO nanocomposites}

Initially, the synthesis of $\mathrm{Chi}-\mathrm{CuO}$ nanocomposites was visually verified by the color change from blue to green and then finally brownish-black color precipitate. The color change may be due to the reaction with copper sulfate, ascorbic acid and chitosan compounds. Ascorbic acid may act as a reducing and stabilizing agent for the formation of $\mathrm{CuO}$ nanocomposites. Similar to our report, Sutradhar et al. [15] visualized color change of copper oxide nanoparticles from light orange to brownish-black color when adding coffee powder extract to copper salt.

\section{Characterization of Chi-CuO nanocomposites}

The $\mathrm{CuO}$ peak was formed around $300 \mathrm{~nm}$ (Fig. 2a). The formation of $\mathrm{Chi}-\mathrm{CuO}$ nanocomposites was monitored by UV-visible spectroscopy and exhibited broad absorbance peak ranging from 270 to $310 \mathrm{~nm}$ due to its surface plasmon resonance (SPR). A maximum was attained at $300 \mathrm{~nm}$ (Fig. 2b) and was in accordance with others' reports [16].

Figure $3 \mathrm{a}-\mathrm{c}$ shows the morphology of synthesized $\mathrm{Chi}-\mathrm{CuO}$ nanocomposites. Figure $3 \mathrm{a}$ shows the prepared nanocomposites were cubical structure with varying size and
Fig. 3b, c shows the irregular shape with the cubical aggregated structure of the prepared $\mathrm{Chi}-\mathrm{CuO}$ nanocomposites. Similar to our study, copper oxide nanoparticles exhibited a cubic structure, synthesized using different capping agents [17]. The EDX spectrum analysis represented in Fig. 3d shows the signal from $\mathrm{Cu}$ together with $\mathrm{C}$ and $\mathrm{O}$, and the elemental composition is represented in Table 1. Thus, the formation of $\mathrm{CuO}$ nanoparticles is confirmed, and $\mathrm{Cu}$ is the main element in synthesized nanoparticles. Other absorbance peaks of $\mathrm{O}$ and $\mathrm{C}$ in the spectrum obtained were mostly due to the emission of X-ray from existing $\mathrm{O}$ - and C-related compounds of ascorbic acid and chitosan [5].

Figure 4 shows the XRD diffraction pattern of the prepared $\mathrm{Chi}-\mathrm{CuO}$ nanocomposites. Diffraction peaks at $2 \theta$ of $12^{\circ}$ and $20^{\circ}$ correspond to (020), (220), which showed that the chitosan had coated on copper oxide. The spectrum also shows the peaks in the range of $22.9^{\circ}, 25.5^{\circ}, 32.2^{\circ}, 45.6^{\circ}$, $53.1^{\circ}, 56.2^{\circ}, 65.9^{\circ}, 69.1^{\circ}$, and $77.4^{\circ}$, which correspond to the (021), (021), (110), (111), (020), (202), (-113), (202) and (111) planes, respectively [18]. The XRD spectrum revealed that the prepared $\mathrm{Chi}-\mathrm{CuO}$ nanocomposites had cubic crystalline structure, and the corresponding planes obtained were matched with the JCPDS File number (JCPDS NO: 05-0061) $[18,19]$. The average crystalline size was calculated using Debye-Scherrer's formula:

$D=0.9 \lambda / \beta \cos \theta$,

where $D$ is the average size of the nanoparticles, $\lambda$ is the wavelength of X-ray, $\beta$ is the FWHM (full width at half maximum) in radians and $\theta$ is the diffraction angle [13]. The average mean crystallite size was found to be $17 \mathrm{~nm}$ from all breath of the refraction.

The FT-IR spectra of the prepared Chi-CuO nanocomposites, chitosan and ascorbic acid are shown in Figs. 5, 6
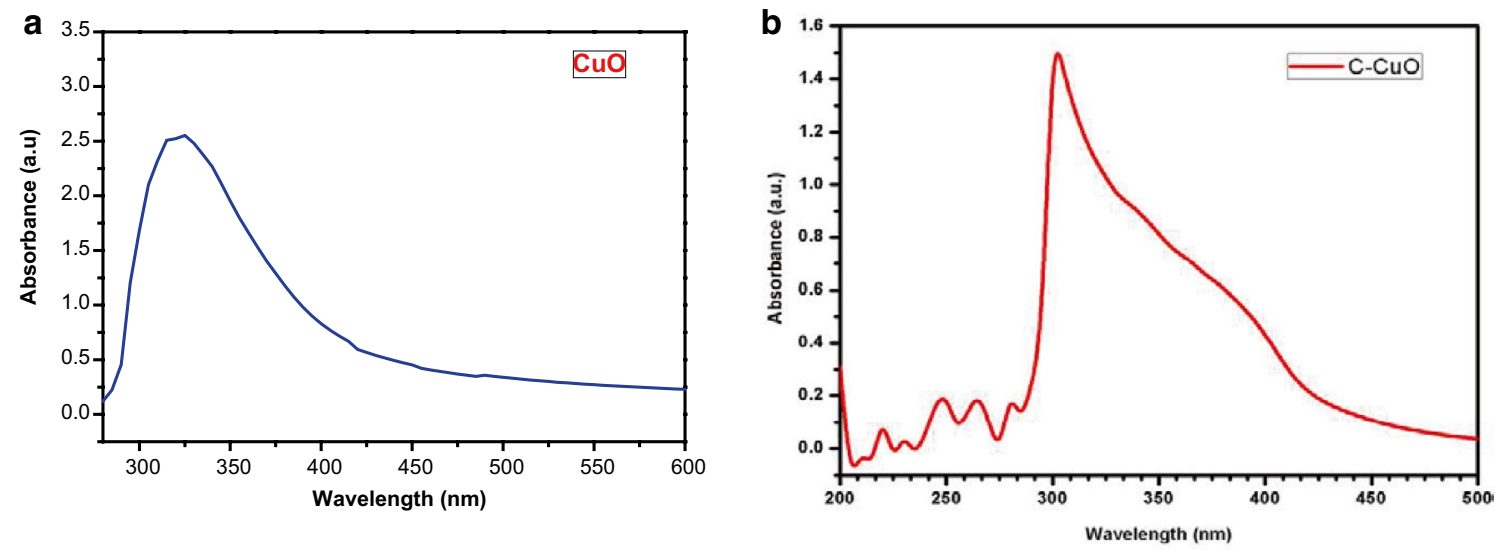

Fig. $2 \mathrm{UV}$-visible spectral absorbance of (a) $\mathrm{CuO}$ and (b) $\mathrm{Chi}-\mathrm{CuO}$ nanocomposites 


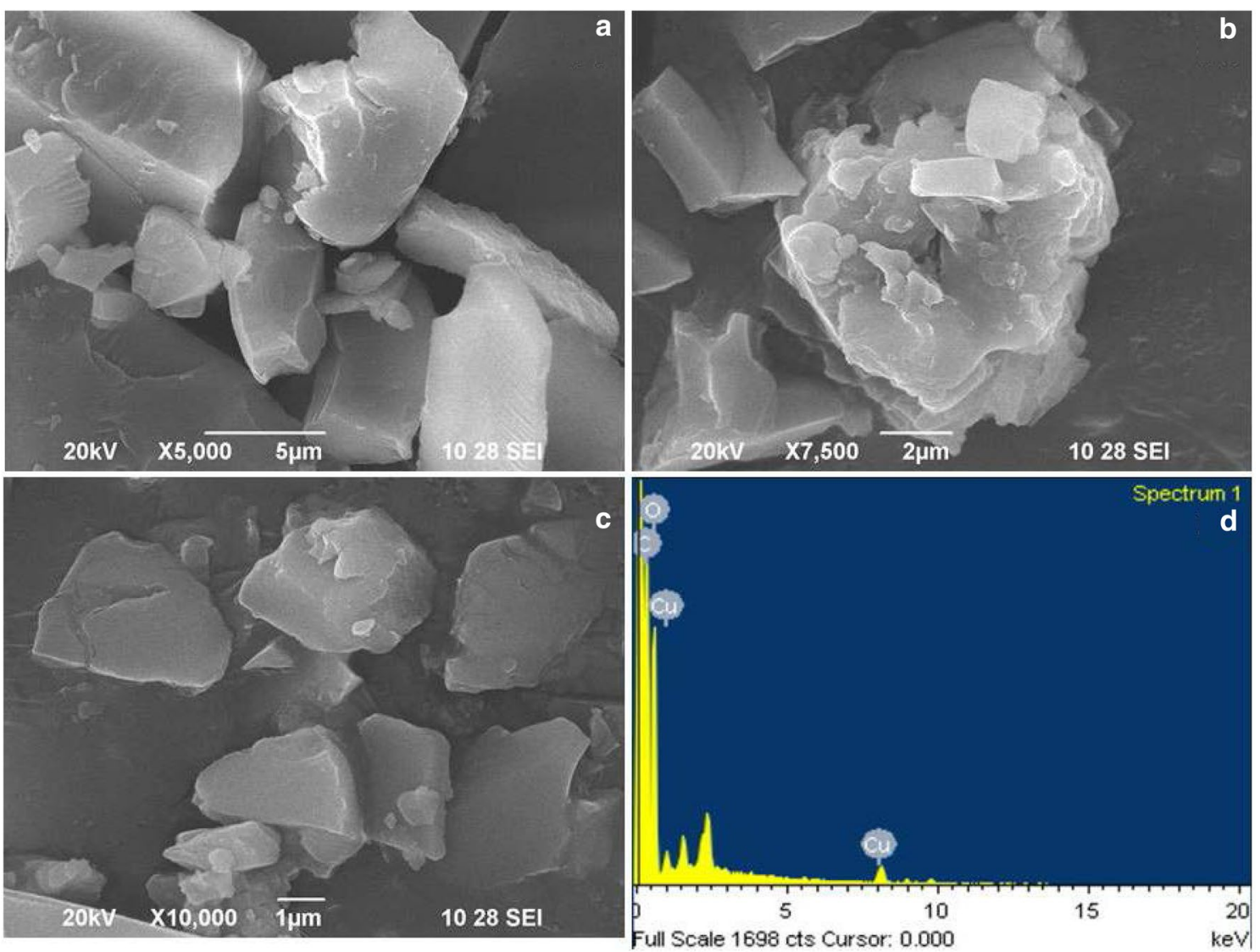

Fig. 3 Electron microscopic observation and elemental analysis of $\mathrm{Chi}-\mathrm{CuO}$ nanocomposites, (a-c) SEM image of Chi-CuO nanocomposites and (d) EDX spectrum of Chi-CuO

Table 1 Elemental

composition of chitosan-CuO nanocomposites

\begin{tabular}{lc}
\hline Element & Weight $\%$ \\
\hline $\mathrm{C}$ & 45.70 \\
$\mathrm{O}$ & 50.54 \\
$\mathrm{Cu}$ & 3.77 \\
Total & 100.0 \\
\hline
\end{tabular}

and 7. The prepared $\mathrm{Chi}-\mathrm{CuO}$ exhibited a strong intensity peak at $3577.14 \mathrm{~cm}^{-1}$, assigned to alkyl $(\mathrm{O}-\mathrm{H})$ stretch possibly of alcohols and phenols. Medium peaks at 1711.90 and $1585.55 \mathrm{~cm}^{-1}$ corresponded to the $\mathrm{C}=\mathrm{O}$ stretch and $\mathrm{C}-\mathrm{C}$ vibrations of carboxylic acids and aromatic compounds. Peaks at 1377.23 and $1069.57 \mathrm{~cm}^{-1}$ assigned to $\mathrm{C}-\mathrm{H}$ and $\mathrm{C}-\mathrm{N}$ stretch indicated the presence of alkanes and aliphatic amines (chitosan). Low-intensity peaks near $800-400 \mathrm{~cm}^{-1}$ represent the presence of metal oxygen [20-22]. FT-IR spectrum from Figs. 6 and 7 clearly shows that the major spectral peaks of the prepared $\mathrm{Chi}-\mathrm{CuO}$ composites are derived from ascorbic acid and chitosan. The presence of these bio and polymer compounds may be responsible for

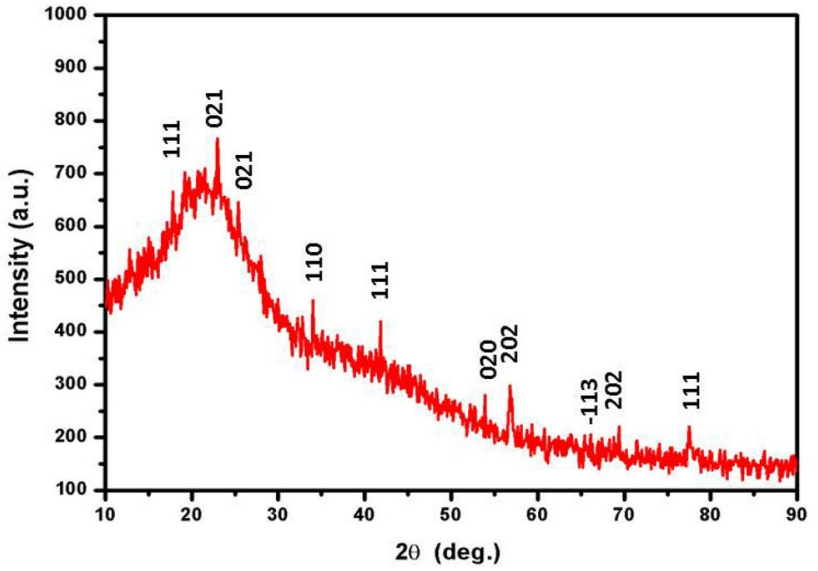

Fig. 4 XRD pattern of the prepared chitosan-copper oxide nanocomposites

the reduction and conversion of synthesized metal nanocomposites $(\mathrm{Chi}-\mathrm{CuO})$ [5]. 


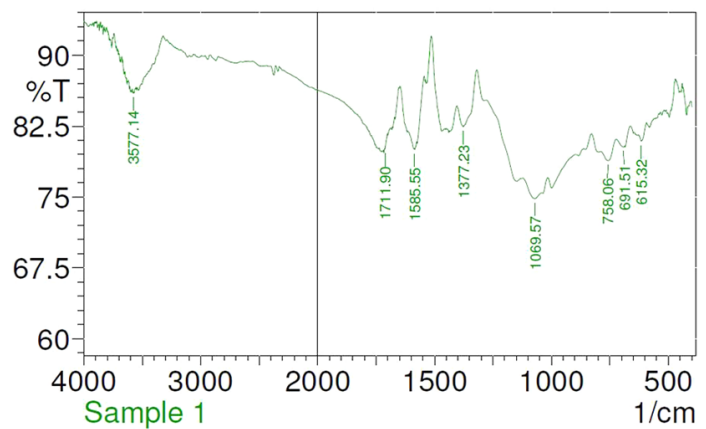

Fig. 5 FT-IR spectrum of the prepared chitosan-copper oxide nanocomposites

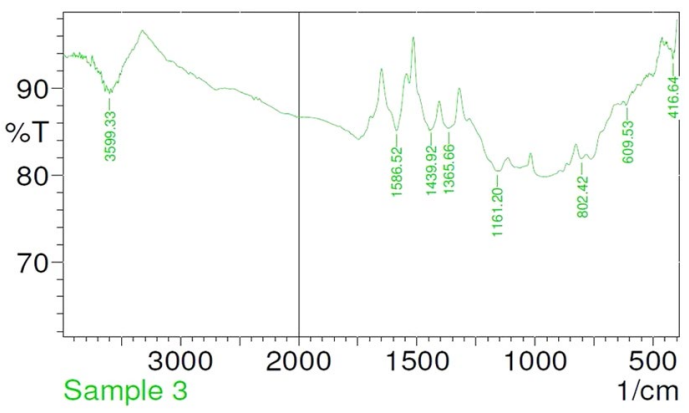

Fig. 6 FT-IR spectrum of chitosan biopolymer

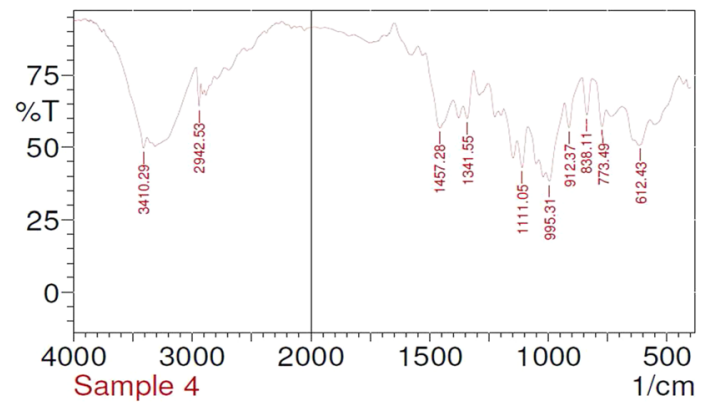

Fig. 7 FT-IR spectrum of ascorbic acid

\section{Anti-microbial activity}

The anti-microbial activity of $\mathrm{Chi}-\mathrm{CuO}$ composites were examined against bacterial and fungal strains using the agar well diffusion method. The highest antibacterial zone of inhibition was recorded against $B$. subtilis, followed by $P$. aeruginosa, E. coli and P. notatum (Fig. 8a-d). Measurement of the inhibitory concentration is shown in Table 2. Increasing concentrations of $\mathrm{Chi}-\mathrm{CuO}$ nanocomposites exhibited increasing activity. The anti-microbial activity of the prepared $\mathrm{Chi}-\mathrm{CuO}$ nanocomposites was similar to that of the control gentamicin $(100 \mu \mathrm{g} / \mathrm{mL})$. The anti-microbial activity mainly depends on the size and shape of the copper oxide nanoparticles [23]. Polymer-coated copper oxide nanocomposites showed potent antibacterial activity compared to $\mathrm{CuO}$ nanocomposites [24]. Chitosan has strong affinity toward metal ions due to the presence of many amine and hydroxyl groups, and thus leading to $\mathrm{Chi}-\mathrm{CuO}$ nanocomposite formation [25]. Ascorbic acid act as a reducing and capping agent to impart stability to the nanocomposite [26]. The antimicrobial property of metal/polymer nanocomposites may be due to the adsorption of bacteria and causes disruption of the membrane [27]. Similar to our results, the antibacterial activity of hybrid chitosan-cerium oxide nanoparticles was recorded against $E$. coli and B. subtilis [28]. Chitosan nanoparticles have biodegradability, biocompatibility, stability and low toxicity and can act as a novel drug carrier [29].

\section{Anti-biofilm activity}

The biofilm inhibition activity of $\mathrm{Chi}-\mathrm{CuO}$ nanocomposites was assayed on $B$. subtilis and $P$. aeruginosa using microtiter plate assays. It was observed that the biofilm inhibition activity of $\mathrm{Chi}-\mathrm{CuO}$ increased in a concentrationdependent manner (Fig. 9). Similar to our study, copper oxide nanocomposites synthesized from medicinal plants showed increased percentage of anti-biofilm activity with the increasing concentration of $\mathrm{CuO}$ [30]. Treatment for $24 \mathrm{~h}$ with $100 \mu \mathrm{g} / \mathrm{mL}$ of $\mathrm{Chi}-\mathrm{CuO}$ composites showed a decrease of 69 and $63 \%$ of the biofilms formed by B. subtilis and $P$. aeruginosa. These results demonstrate that synthesized $\mathrm{Chi}-\mathrm{CuO}$ nanocomposites induce detachment of $B$. subtilis and $P$. aeruginosa biofilms, with efficient concentration of the prepared nanocomposites. Similar to our results, Kaliswarlal et al. [31] also reported the inhibition of biofilm formation, irrespective of the species tested. 
Fig. 8 Anti-microbial activity of $\mathrm{C}-\mathrm{CuO}$ nanocomposites against (a) B. subtilis, (b) $P$. aeruginosa, (c) E. coli and (d) $P$. notatum with different concentrations ( $A a$ ascorbic acid; control, gentamicin)

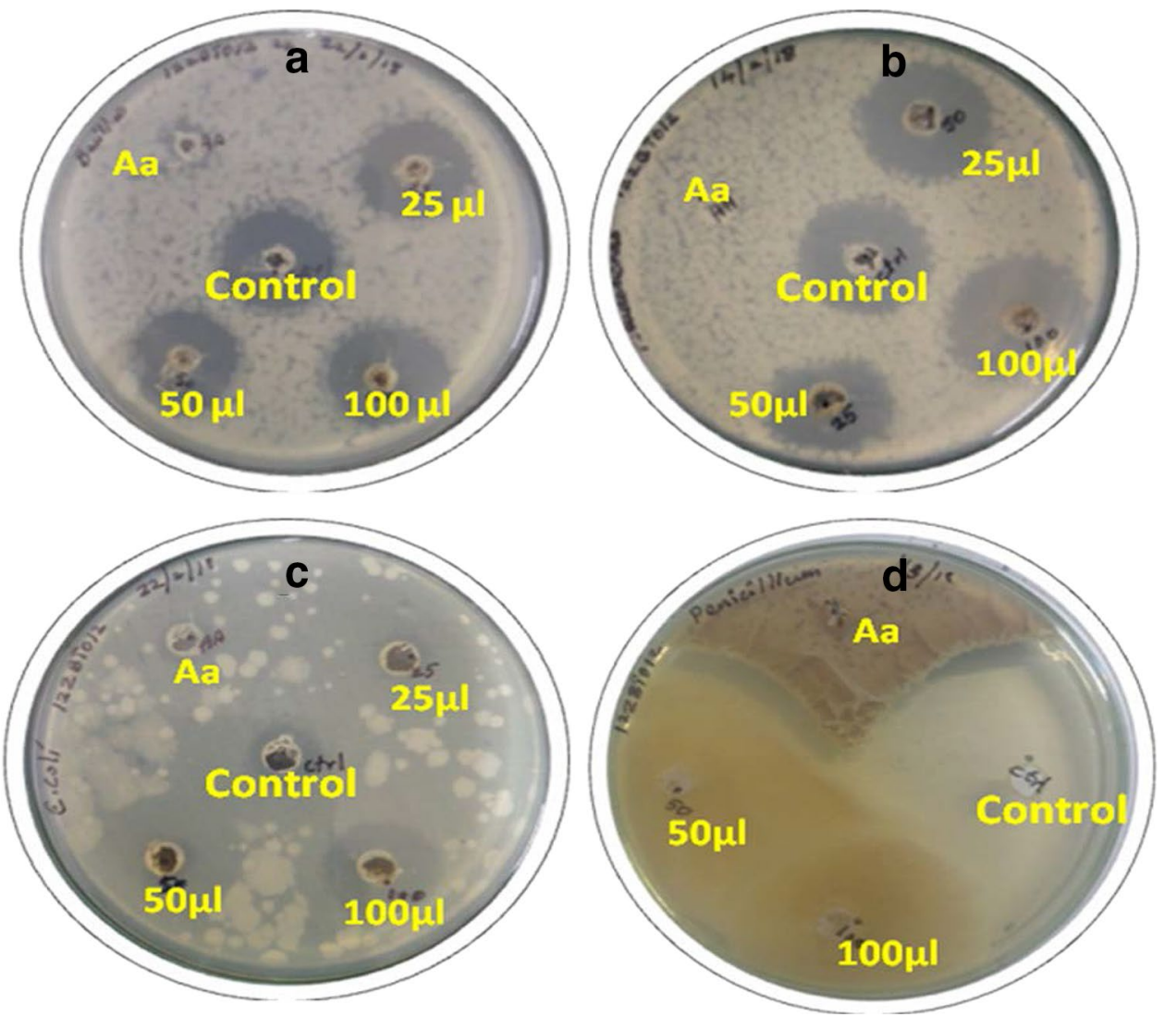

Sporicidal activity

Table 2 Anti-microbial activity of $\mathrm{Chi}-\mathrm{CuO}$ nanocomposites showing the zone of inhibition

\begin{tabular}{lcrrr}
\hline Species & \multicolumn{4}{l}{ Zone of inhibition $(\mathrm{mm})$} \\
\cline { 2 - 5 } & Gentamicin & \multicolumn{1}{c}{$25 \mu \mathrm{L}$} & \multicolumn{1}{c}{$50 \mu \mathrm{L}$} & $100 \mu \mathrm{L}$ \\
\hline B. subtilis & $9 \pm 0.5$ & $6.5 \pm 0.5$ & $7 \pm 0.5$ & $8 \pm 0.5$ \\
E. coli & $9 \pm 0.5$ & $6 \pm 0.5$ & $6 \pm 0.5$ & $8 \pm 0.5$ \\
$P$. aeruginosa & $8 \pm 0.5$ & $6 \pm 0.5$ & $6.5 \pm 0.5$ & $8 \pm 0.5$ \\
P. notatum & $11 \pm 0.5$ & & $10 \pm 0.5$ & $10 \pm 0.5$ \\
\hline
\end{tabular}

B. subtilis

- $P$. aeruginosa

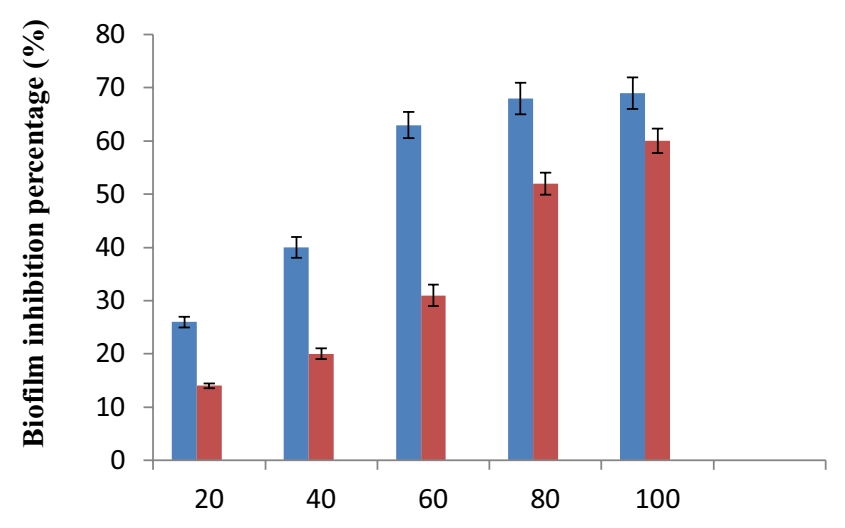

Nanocomposite concentration $(\mu \mathrm{g} / \mathrm{mL})$

Fig. 9 Biofilm inhibition percentage of the prepared $\mathrm{C}-\mathrm{CuO}$ nanocomposites
Ascorbic acid-mediated Chi-CuO nanocomposites showed sporicidal activity by effectively killing $98 \%$ B. subtilis spores. The control plate contains only the medium and the diluted spores of $B$. subtilis which have uncountable colonies, whereas the nanocomposite inhibits the growth of the spores and the growth is countable. The sporicidal activity is shown in Fig. 10. Overall, eco-friendly prepared cubical-shaped $\mathrm{Chi}-\mathrm{CuO}$ nanocomposites exhibited good anti-microbial, sporicidal and anti-biofilm activity similar to other researchers [32].

\section{Conclusion}

$\mathrm{CuO}$ polymer nanocomposites were synthesized using ascorbic acid as reducing agent and then chitosan was coated on prepared $\mathrm{CuO}$ solutions. The prepared $\mathrm{Chi}-\mathrm{CuO}$ nanocomposites were cubical shaped with an average size of $\sim 17 \mathrm{~nm}$ as determined by SEM and XRD. The prepared nanocomposites showed significant antibacterial activity and potent anti-fungal activity. Furthermore, $\mathrm{Chi}-\mathrm{CuO}$ nanocomposites showed sporicidal activity against B. subtilis spores' 
Fig. 10 Sporicidal activity of Chi-CuO nanocomposites against $B$. subtilis spores: (a) control and (b) Chi-CuO NPs
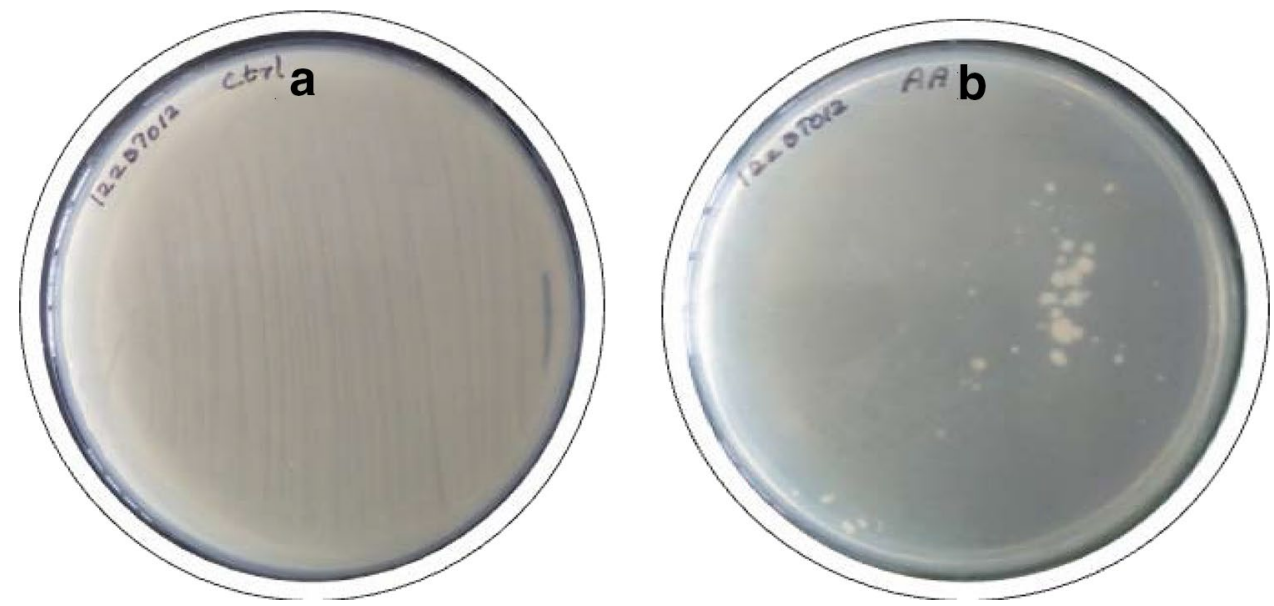

potential biofilm inhibition activity against $B$. subtilis and $P$. aeruginosa.

Acknowledgements The authors like to thank the management of Kongunadu Arts and Science College for providing facilities and we acknowledge the Department of Nano science, Karunya University, Coimbatore, for extending their nanoparticles characterization facilities (SEM, EDX and FT-IR).

\section{Compliance with ethical standards}

Conflict of interest The authors have declared no conflict of interest.

Open Access This article is distributed under the terms of the Creative Commons Attribution 4.0 International License (http://creativeco mmons.org/licenses/by/4.0/), which permits unrestricted use, distribution, and reproduction in any medium, provided you give appropriate credit to the original author(s) and the source, provide a link to the Creative Commons license, and indicate if changes were made.

\section{References}

1. Faraji, S., Anim, F.N.: Microwave-assisted synthesis of metal oxide/hydroxide composite electrodes for high power super capacitors-a review. J. Power Sources 1, 338-360 (2014)

2. Larsen, T.H., Sigman, M., Ghezelbash, A., Doty, R.C., Korgel, v: Solventless synthesis of copper sulfide nanorods by thermolysis of a single source thiolate-derived precursor. J. Am. Chem. Soc. 125, 5638-5649 (2003)

3. Lee, Y., Choi, J.R., Lee, K.J., Stott, N.E., Kim, D.: Large-scale synthesis of copper nanoparticles by chemically controlled reduction for applications of inkjet-printed electronics. Nanotechnology 19, 415604 (2008)

4. Xiang, Q., Meng, G., Zhang, Y., Xu, J., Xu, P., Pan, Q., Yu, W.: $\mathrm{Ag}$ nanoparticle embedded-ZnO nanorods synthesized via a photochemical method and its gas-sensing properties. Sens. Actuators B Chem. 143, 635-640 (2010)

5. Bharathi, D., Josebin, M.D., Vasantharaj, S., Bhuvaneshwari, V.: Biosynthesis of silver nanoparticles using stem bark extracts of Diospyros montana and their antioxidant and antibacterial activities. J. Nanostruct. 8, 83-92 (2018)
6. Laxminarayan, R., Duse, A., Wattal, C., Zaidi, A.K., Wertheim, H.F., Sumpradit, N., Vlieghe, E., Hara, G.L., Gould, I.M., Goossens, H., Greko, C.: Antibiotic resistance-the need for global solutions. Lancet Infect. Dis. 13, 1057-1098 (2013)

7. Wang, X., Hu, C., Liu, H., Du, G., He, X., Xi, Y.: Synthesis of $\mathrm{CuO}$ nanostructures and their application for nonenzymatic ascorbic acid sensing. Sens. Actuators B Chem. 144, 220-225 (2010)

8. Usman, M.S., El Zowalaty, M.E., Shameli, K., Zainuddin, N., Salama, M., Ibrahim, N.A.: Synthesis, characterization, and antimicrobial properties of copper nanoparticles. Int. J. Nanomed. 8, 4467 (2013)

9. Drury, J.L., Mooney, D.J.: Hydrogels for tissue engineering: scaffold design variables and applications. Biomaterials 24, 43374351 (2013)

10. Torlak, E., Sert, D.: Antibacterial effectiveness of chitosan-propolis coated polypropylene films against foodborne pathogens. Int. J. Biol. Macromol. 60, 52-55 (2013)

11. Tripathi, S., Mehrotra, G.K., Dutta, P.K.: Chitosan-silver oxide nanocomposite film: preparation and antimicrobial activity. Bull. Mater. Sci. 34, 29-35 (2011)

12. Naika, H.R., Lingaraju, K., Manjunath, K., Kumar, D., Nagaraju, G., Suresh, D., Bagabhusana, H.: Green synthesis of $\mathrm{CuO}$ nanoparticles using Gloriosa superba L. extract and their antibacterial activity. J. Taibah Univ. Sci. 9, 7-12 (2015)

13. Bharathi, D., Vasantharaj, S., Bhuvaneshwari, V.: Green synthesis of silver nanoparticles using Cordia dichotoma fruit extract and its enhanced antibacterial, anti-biofilm and photo catalytic activity. Mater. Res. Express (2018). https://doi.org/10.1088/2053-1591/ aac2ef

14. Barapatre, A., Aadil, K.R., Jha, H.: Synergistic antibacterial and antibiofilm activity of silver nanoparticles biosynthesized by lignin-degrading fungus. Bioresour. Bioprocess. 3, 8-15 (2016)

15. Sutradhar, P., Saha, M., Maiti, D.: Microwave synthesis of copper oxide nanoparticles using tea leaf and coffee powder extracts and its antibacterial activity. J. Nanostruct. 4, 86-90 (2014)

16. Sulaiman, G.M., Tawfeeq, A.T., Jaaffer, M.D.: Biogenic synthesis of copper oxide nanoparticles using Olea europaea leaf extract and evaluation of their toxicity activities: an in vivo and in vitro study. Biotechnol. Prog. 34, 218-230 (2018)

17. Ren, G., Hu, D., Cheng, E.W., Vargas-Reus, M.A., Reip, P., Allaker, R.P.: Characterisation of copper oxide nanoparticles for antimicrobial applications. Int. J. Antimicrob. Agents 33, 587-590 (2009)

18. Kayani, Z.N., Umer, M., Riaz, S., Naseem, S.: Characterization of copper oxide nanoparticles fabricated by the sol-gel method. J. Electron. Mater. 244, 3704-3709 (2015) 
19. Kumar, M., Swamy, B.K.: Role of heat on the development of electrochemical sensors on bare and modified $\mathrm{Co} 3 \mathrm{O} 4 / \mathrm{CuO}$ composite nanopowder carbon paste electrodes. Mater. Sci. Eng. C 58, 142-152 (2015)

20. Vasantharaj, S., Sripriya, N., Shanmugavel, M., Manikandan, E., Gnanamani, A., Senthilkumar, P.: Surface active gold nanoparticles biosynthesis by new approach for bionanocatalytic activity. J. Photochem. Photobiol. B 179, 119-125 (2018)

21. Basumallick, S., Santra, S.: Chitosan coated copper-oxide nano particles: a novel electro-catalyst for $\mathrm{CO} 2$ reduction. RSC Adv. 4, 63685-63690 (2014)

22. Salaheldin, H.I., Almalki, M.H., Hezma, A.E., Osman, G.E.: Facile synthesis of silver nanoparticles mediated by polyacrylamide-reduction approach to antibacterial application. IET Nanobiotechnol. 11, 448-453 (2016)

23. Satyvaldiev, A.S., Zhasnakunov, Z.K., Omurzak, E., Doolotkeldieva, T.D., Bobusheva, S.T., Orozmatova, G.T., Kelgenbaeva, Z.: Copper nanoparticles: synthesis and biological activity. IOP Conf. Ser. Mater. Sci. Eng. (2018). https://doi. org/10.1088/1757-899x/302/1/012075

24. Cioffi, N., Torsi, L., Ditaranto, N., Tantillo, G., Ghibelli, L., Sabbatini, L., Bleve-Zacheo, T., D’Alessio, M., Zambonin, P.G., Traversa, E.: Copper nanoparticle/polymer composites with antifungal and bacteriostatic properties. Chem. Mater. 17, 5255-5262 (2015)

25. Varma, A.J., Deshpande, S.V., Kennedy, J.F.: Metal complexation by chitosan and its derivatives: a review. Carbohydr. Polym. 55, 77-93 (2004)
26. Umer, A., Naveed, S., Ramzan, N., Rafique, M.S., Imran, M.: A green method for the synthesis of copper nanoparticles using L-ascorbic acid. Matéria (Rio de Janeiro) 19, 197-203 (2014)

27. Syame, S.M., Mohamed, W.S.: Synthesis of copper-chitosan nanocomposites and its application in treatment of local pathogenic isolates bacteria. Orient. J. Chem. 33, 2959-2969 (2017)

28. Senthilkumar, R.P., Bhuvaneshwari, V., Ranjithkumar, R., Sathiyavimal, S., Malayaman, V., Chandarshekar, B.: Synthesis, characterization and antibacterial activity of hybrid chitosancerium oxide nanoparticles: as a bionanomaterials. Int. J. Biol. Macromol. 104, 1746-1752 (2017)

29. Shrestha, A., Zhilong, S., Gee, N.K., Kishen, A.: Nanoparticulates for antibiofilm treatment and effect of aging on its antibacterial activity. J. Endod. 36, 1030-1035 (2010)

30. Vaidehi, D., Bhuvaneshwari, V., Amsaveni, R., Kalaiselvi, M., Sivaranjini, A.: Novel chitosan nanoparticles as drug carriers in cancer therapy. J. Polym. Mater. 34, 197-206 (2017)

31. Kalishwaralal, K., BarathManiKanth, S., Pandian, S.R., Deepak, V., Gurunathan, S.: Silver nanoparticles impede the biofilm formation by Pseudomonas aeruginosa and Staphylococcus epidermidis. Colloids Surf. B Biointerfaces 79, 340-344 (2010)

32. Haldorai, Y., Shim, J.J.: Multifunctional chitosan-copper oxide hybrid material: photocatalytic and antibacterial activities. Int. J. Photoenergy 2013, 8 (2013)

Publisher's Note Springer Nature remains neutral with regard to jurisdictional claims in published maps and institutional affiliations. 